\title{
Editorial - Autoria e coautoria de trabalhos científicos: discussões sobre critérios para legitimação de coautoria e parâmetros de integridade científica
}

\author{
Editorial - Authorship and co-authorship of scientific manuscripts: \\ discussions about criteria for legitimation of co-authorship and \\ parameters of scientific integrity
}

\section{Vinicius Gomes de Vasconcellos ${ }^{1}$}

Universidade Estadual de Goiás, Goiânia, Goiás, Brasil Instituto Brasiliense de Direito Público, Brasília, Distrito Federal, Brasil vinicius.vasconcellos@ueg.br lattes.cnpq.br/9628659956663949 orcid.org/0000-0003-2020-5516

p publons.com/a/1174099/

\begin{abstract}
Resumo: Este trabalho pretende analisar a temática da autoria e coautoria de artigos científicos, especialmente em relação ao campo do Direito. Basicamente, almeja-se responder: quando um pesquisador pode, legitimamente, ser indicado como coautor de um artigo científico? Trata-se de questão pertinente, tendo em vista os impactos acadêmicos, sociais e econômicos da definição de autoria, além da importância em termos de responsabilização e integridade da produção científica. Assim, serão analisados os critérios de coautoria e as diretrizes básicas sobre a temática.
\end{abstract}

Palavras-chave: editorial; coautoria; integridade científica; autoria honorária; autoria fantasma; editoração.

1 Doutor em Direito pela Universidade de São Paulo, com período de sanduíche na Universidad Complutense de Madrid/ESP (bolsa PDSE/CAPES) e estágio de pós-doutoramento pela Universidade Federal do Rio de Janeiro. Mestre em Ciências Criminais pela PUCRS. Professor permanente do Instituto Brasiliense de Direito Público - IDP/DF (mestrado/doutorado). Professor efetivo da Universidade Estadual de Goiás. Editor-chefe da RBDPP. Assessor de Ministro no Supremo Tribunal Federal. 
ABSTRACT: This paper aims to analyze the theme of authorship and coauthorship of scientific articles, especially in relation to Law field of knowledge. Basically, its aim is to answer: when can a researcher legitimately be nominated as coauthor of a scientific paper? This is a pertinent issue, considering the academic, social and economic impacts of the definition of authorship, as well as its importance in terms of accountability and integrity of scientific production. Thus, it will analyze the co-authorship conditions and the basic standards on the subject.

KEY-wORDS: editorial; co-authorship; scientific integrity; gift authorship; ghost authorship; editing.

As tendências contemporâneas de ampliação da pressão sobre pesquisadores por aumento de produtividade, do número de publicações e do impacto ${ }^{2}$ acarretam diversas consequências ao campo científico e, sem dúvidas, o Direito não passaria imune por tal cenário. O fenômeno do publish or perish finda por causar tensões diversas, como fragilizações em questões de integridade científica e ética na publicação de trabalhos acadêmicos. ${ }^{3}$ Diante disso, o papel do periódico científico e a atuação de editores e avaliadores se sobressaem em importância para tentar verificar e conter eventuais práticas abusivas. ${ }^{4}$

Assim, questão que tem atraído atenção se relaciona com o aumento do número de artigos publicados em coautoria, em outras áreas

2 Sobre impacto e possíveis distinções para a sua verificação na área do Direito e do processo penal, ver: CAPPARELLI, Bruna; GIACOMOLLI, Nereu J. Editorial: A avaliação do Impact Factor na publicação científica de Direito Processual Penal. Revista Brasileira de Direito Processual Penal, Porto Alegre, vol. 3, n. 3, p. 789-806, set./dez. 2017.

3 WINCK, J.C.; WEDZICHA, J.A.; FONSECA, J.A.; AZEVEDO, L.F. To publish or perish: how to review a manuscript. Revista Portuguesa de Pneumologia, vol. 17, n. 2, p. 96-103, 2011.

4 Sobre isso: VASCONCELLOS, Vinicius G. Editorial: a função do periódico científico e do editor para a produção do conhecimento no Direito e nas ciências criminais. Revista Brasileira de Direito Processual Penal, Porto Alegre, vol. 3, n. 1, p. 9-17, jan./abr. 2017; MINORELLI, Lucas; SILVA, Willians M. Publicações em periódicos de ciências criminais no Brasil: uma perspectiva de editores. Revista dos Tribunais, São Paulo, v. 1009, p. 359-381, nov. 2019 
do conhecimento, mas também no Direito. ${ }^{5}$ Trata-se de problemática extremamente pertinente em editoração e integridade científica, tendo em vista o estabelecimento de regras e critérios para verificação e legitimação da coautoria. Basicamente, almeja-se responder: quando um pesquisador pode, legitimamente, ser indicado como coautor de um artigo científico?

Na prática editorial, relatam-se casos de abusos e violações à integridade científica. ${ }^{6}$ Normalmente, cita-se o costume de inclusão de "autores honorários", que não contribuíram efetivamente com a pesquisa e não deveriam ser ali indicados. ${ }^{7}$ Há também casos de "autoria fantasma", em que aquele pesquisador que efetivamente realizou o estudo não é indicado como autor. ${ }^{8}$ Diante das demandas por produtividade, também se noticiam situações de "trocas de favores", em que pesquisadores se colocam mutuamente em trabalhos realizados de modo individual.

Sem dúvidas, tal questão se relaciona com diversos aspectos da produção do conhecimento científico, pois autoria garante o reconhecimento e a certificação pelo trabalho desenvolvido, possuindo importantes reflexos acadêmicos, sociais e financeiros, além de determinar a responsabilidade e a possibilidade de controle sobre o artigo publicado. Assim, órgãos internacionais de integridade científica, como o Committee on Publication Ethics (COPE), o International Committee of Medical Journal Editors (ICMJE) e a Scielo, recomendam que os periódicos adotem políticas públicas e transparentes sobre coautoria e, inclusive, solicitem

5 CONCEIÇÃO, Maria Inês G. Editorial: os colaboradores em um artigo científico. Psicologia: teoria e pesquisa, Brasília, v. 24, n. 2, p. iii-iv, abr./jun. 2008. p. iii.

6 REGO, Sergio. Índice H, Autoria e Integridade na Produção Científica. Revista Brasileira de Educação Médica, Rio de Janeiro, v. 34, n. 2, p. 189-190, abr./jun. 2010. p. 190; KROKOSCZ, Marcelo. Autoria na redação científica. Informação \& Informação, Londrina, v. 20, n. 1, p. 319-333, jan./abr. 2015. p. 327-328.

7 PETROIANU, Andy. Critérios para autoria de um trabalho científico. DST Jornal brasileiro de doenças sexualmente transmissíveis, v. 24, n. 2, p. 99-103, 2012. p. 102.

8 DONATO, Helena. Autoria na publicação científica. Revista da Sociedade Portuguesa de Medicina Física e Reabilitação, v. 25, n. 1, p. 8-10, 2014. p. 8. 
aos autores declarações de integridade em coautoria e especificação de contribuições de cada coautor. ${ }^{9}$

Há revistas que objetivamente definem um número máximo de coautores, como três ou cinco. Na área de ciências criminais, pode-se verificar o tratamento da matéria em dois periódicos de referência. ${ }^{10}$ Atualmente, a RBCCRIM não possui regra sobre limitação de coautores. ${ }^{11}$ Já a REC limita em 3 autores por artigo, sem previsão de exceções. ${ }^{12}$

Por outro lado, há periódicos que adotam um critério qualitativo, com a verificação da atenção aos requisitos de coautoria de cada pesquisador indicado, conforme as atividades desempenhadas na pesquisa. Nesse sentido, inicialmente devemos descrever, brevemente, as principais funções/atividades desempenhadas por um pesquisador no desenvolvimento de um trabalho científico (artigo, TCC, dissertação, tese). Para tanto, será utilizada como base a terminologia sugerida pelo Projeto CRedit (Contributor Roles Taxonomy) ${ }^{13}$ do CASRAI,${ }^{14}$ atualmente recomendada pela Scielo.

9 COPE. Documento de discussão: Autoria. Disponível em: <https://publicationethics.org/files/COPE_DD_A4_Authorship_SEPT19_SCREEN_AW.pdf >. Acesso em: 23 dez. 2019; Disponível em: <http://www.icmje.org/recommendations/browse/roles-and-responsibilities/defining-the-role-of-authors-and-contributors.html>. Acesso em: 23 dez. 2019; SCIELO. Critérios Scielo Brasil. Disponível em: <http://www.scielo.br/avaliacao/Criterios\%20SciELO\%20Brasil.pdf>. Acesso em: 23 dez. 2019.

10 Sobre isso, em revistas da área da Saúde, ver: MONTEIRO, Rosangela; JATENE, Fabio B.; GOLDENBERG, Saul; POBLACIÓN, Dinah A.; FELLIZZON, Rosely F. Critérios de autoria em trabalhos científicos: um assunto delicado e polêmico. Revista Brasileira de Cirurgia Cardiovascular, v. 19, n. 4, p. III-VIII, 2004.

11 Disponível em: <https://www.ibccrim.org.br/rbccrim_normas_publicacao>. Acesso em: 23 dez. 2019

12 Disponível em: <http://www.itecrs.org/edicoes/regras>. Acesso em: 23 dez. 2019

13 Disponível em: <https://casrai.org/credit/>. Acesso em 23 dez. 2019. Sobre isso: BRAND, Amy; ALLEN, Liz; ALTMAN, Micah; HLAVA, Marjorie; SCOTT, Jo. Beyond authorship: attribution, contribution, collaboration, and credit. Learned Publishing, v. 28, n. 2, p. 151-155, 2015.

14 Trata-se de projeto que almeja padronizar e uniformizar informações relacionadas à pesquisa científica. Sobre isso, ver: <https://casrai.org/about> . Acesso em 23 dez. 2019. 


\begin{tabular}{|c|c|}
\hline $\begin{array}{l}\text { Conceptualização } \\
\text { (Conceptualization) }\end{array}$ & $\begin{array}{l}\text { Ideias; formulação ou aprimoramento das metas e } \\
\text { objetivos relevantes da pesquisa. }\end{array}$ \\
\hline $\begin{array}{l}\text { Organização de dados } \\
\text { (Data curation) }\end{array}$ & $\begin{array}{l}\text { Administração de atividade para anotar (produzir } \\
\text { dados), limpar dados e manter os dados da } \\
\text { pesquisa (incluindo programação de software, } \\
\text { quando necessário para interpretar os próprios } \\
\text { dados) para uso inicial ou posterior reúso. }\end{array}$ \\
\hline $\begin{array}{l}\text { Análise formal } \\
\text { (Formal Analysis) }\end{array}$ & $\begin{array}{l}\text { Aplicação de técnicas de estatística, matemática ou } \\
\text { computacionais, além de outras técnicas formais } \\
\text { para analisar e sistematizar os dados de estudo. }\end{array}$ \\
\hline $\begin{array}{l}\text { Obtenção de } \\
\text { financiamento } \\
\text { (Funding acquisition) }\end{array}$ & $\begin{array}{l}\text { Obtenção de suporte financeiro para o projeto } \\
\text { principal da publicação. }\end{array}$ \\
\hline $\begin{array}{l}\text { Pesquisa } \\
\text { (Investigation) }\end{array}$ & $\begin{array}{l}\text { Realizar a pesquisa e o processo de investigação, } \\
\text { especificamente com a execução dos } \\
\text { experimentos, ou coleta de dados e provas. }\end{array}$ \\
\hline $\begin{array}{l}\text { Metodologia } \\
\text { (Methodology) }\end{array}$ & $\begin{array}{l}\text { Desenvolvimento ou desenho da metodologia, } \\
\text { criação de modelos. }\end{array}$ \\
\hline $\begin{array}{l}\text { Administração do } \\
\text { projeto (Project } \\
\text { administration) }\end{array}$ & $\begin{array}{l}\text { Administração e coordenação para o planejamento } \\
\text { e execução da atividade de pesquisa. }\end{array}$ \\
\hline Recursos (Resources) & $\begin{array}{l}\text { Concessão de materiais, reagentes, pacientes, } \\
\text { amostra de laboratório, animais, instrumentos, } \\
\text { recursos de computador ou outras ferramentas } \\
\text { de análise. }\end{array}$ \\
\hline Software & $\begin{array}{l}\text { Programação, desenvolvimento de software; design } \\
\text { de programas de computador; implementação de } \\
\text { códigos de computador ou algoritmos de suporte; } \\
\text { teste de códigos já existentes. }\end{array}$ \\
\hline $\begin{array}{l}\text { Supervisão } \\
\text { (Supervision) }\end{array}$ & $\begin{array}{l}\text { Supervisão e responsabilidade de liderança } \\
\text { sobre a atividade de planejamento e execução da } \\
\text { pesquisa, incluindo guia por mentor externo à } \\
\text { equipe principal. }\end{array}$ \\
\hline Validação (Validation) & $\begin{array}{l}\text { Verificação, tanto como parte da atividade } \\
\text { ou separadamente, sobre a replicação e } \\
\text { reprodutibilidade dos resultados experimentos } \\
\text { ou outras implicações da pesquisa. }\end{array}$ \\
\hline
\end{tabular}




\begin{tabular}{|l|l|}
\hline $\begin{array}{l}\text { Visualização } \\
\text { (Visualization) }\end{array}$ & $\begin{array}{l}\text { Preparação, criação e/ou apresentação do } \\
\text { trabalho publicado, especificamente visualização } \\
\text { e apresentação de dados. }\end{array}$ \\
\hline $\begin{array}{l}\text { Redação - manuscrito } \\
\text { original (Writing - } \\
\text { original draft) }\end{array}$ & $\begin{array}{l}\text { Preparação, criação ou apresentação do } \\
\text { trabalho publicado, especificamente redação do } \\
\text { manuscrito original (incluindo tradução) }\end{array}$ \\
\hline $\begin{array}{l}\text { Redação - revisão } \\
\text { e edição (Writing - } \\
\text { review \& editing) }\end{array}$ & $\begin{array}{l}\text { Preparação, criação ou apresentação do trabalho } \\
\text { publicado por membros do grupo de pesquisa } \\
\text { original, especificamente revisão crítica, } \\
\text { comentários e correção, incluindo fases de pré ou } \\
\text { pós-publicação. }\end{array}$ \\
\hline
\end{tabular}

Tabela desenvolvida a partir de tradução livre dos conceitos e definições apresentados pelo CRediT da CASRAI. Disponível em: <https://casrai.org/credit/>. Acesso em 23 dez. 2019.

Conforme orientações indicadas por Scielo, os dois critérios mínimos de autoria são: "a. Participar ativamente da discussão dos resultados; b. Revisão e aprovação da versão final do trabalho". ${ }^{15}$ Em âmbito internacional, costuma-se adotar os parâmetros definidos pelo International Committee of Medical Journal Editors (ICMJE), que indica os seguintes papeis mínimos para autorizar a listagem do pesquisador como autor do artigo: “1) contribuições substanciais na concepção e projeto da pesquisa; ou coleta, análise e interpretação de dados para o trabalho, e; 2) redação do artigo ou revisão crítica com contribuições intelectuais relevantes; 3) aprovação final da versão para ser publicada, e; 4) consentimento em ser responsabilizado por todos os aspectos do trabalho ao assegurar que questões relacionadas à precisão e à integridade de qualquer parte do trabalho estão devidamente investigadas e resolvidas". ${ }^{16}$

15 Disponível em: <http://www.scielo.br/avaliacao/Criterios\%20SciELO\%20 Brasil.pdf>. Acesso em: 23 dez. 2019.

16 Disponível em: <http://www.icmje.org/recommendations/browse/roles -and-responsibilities/defining-the-role-of-authors-and-contributors.html>. Acesso em: 23 dez. 2019 (tradução livre). Nos termos lá indicados: "Destacase que esses critérios não são destinados a dolosamente excluir colegas que poderiam atender aos critérios de autoria por meio de denegação de oportunidade para cumprir os requisitos 2 e 3 . Assim, recomenda-se que todos os 
Ou seja, pensa-se que, para poder ser considerado coautor do trabalho, o pesquisador não precisa necessariamente atuar em todas as funções e etapas indicadas na tabela acima, mas deve cumprir requisitos básicos de atuação no sentido de: 1) contribuir efetivamente com a pesquisa (a) em sua concepção ou desenvolvimento, e (b) em sua redação ou revisão crítica; 2) aprovar a versão final do artigo e concordar com as ideias sustentadas; e, 3) responsabilizar-se por garantir a integridade da pesquisa e do artigo em sua totalidade.

Portanto, existem casos em que o pesquisador pode contribuir para a pesquisa, mas não de modo suficiente a ser considerado como coautor. Nesse sentido, costuma-se citar exemplos de atividades que, embora comuns, por si só (sem outras contribuições), não qualificam o pesquisador como coautor: obtenção de financiamento, supervisão geral do grupo de pesquisa ou apoio administrativo geral, revisão técnica e gramatical, diagramação e revisão final. ${ }^{17}$ Além disso, outra função que costuma gerar certas imprecisões é aquela desempenhada pelo tradutor, que, embora realize tarefa extremamente complexa e relevante, não é exclusivamente por isso caracterizado como coautor.

Sem dúvidas, uma das questões que gera maiores discussões diz respeito à inclusão do/a orientador/a como coautor. Aqui há diversas visões distintas entre culturas nas diferentes áreas do conhecimento, além de fortes discussões dentro do próprio campo do Direito. Primeiramente, o problema se coloca, por óbvio, quando o/a orientador/a publica juntamente ao aluno algum resultado ou parte da pesquisa realizada pelo orientando. Se houver uma pesquisa conjunta, em um tema estudado por ambos, caracteriza-se a coautoria conforme os critérios e requisitos acima.

Agora, por outro lado, as atividades inerentes à “orientação”, por si sós, não parecem ser suficientes para autorizar a inclusão do orientador como coautor da pesquisa realizada pelo aluno. E prova cabal disso é o fato de que, por óbvio, nem sempre o orientador irá concordar totalmente

pesquisadores que atenderem ao primeiro requisito, tenham a oportunidade de cumprir com as funções 2 e 3 " (tradução livre).

17 De modo semelhante: <http://www.icmje.org/recommendations/browse/ roles-and-responsibilities/defining-the-role-of-authors-and-contributors. html>. Acesso em: 23 dez. 2019 (tradução livre). 
com a tese sustentada pelo orientando. Nesse caso, o orientador, embora assim tenha atuado ao desempenhar as atividades inerentes a uma correta "orientação", não poderá ser indicado como coautor de uma tese com a qual não concorda.

Portanto, pensa-se que a orientação entre professor e aluno não é critério suficiente para coautoria. Não se quer dizer que o/a orientador/a nunca pode ser coautor de trabalho em conjunto com o orientando, mas, nesse caso (como em todos os outros), deve-se cumprir com os requisitos mínimos para configuração de coautoria acima expostos. Basicamente, o/a orientador/a deve "colocar a mão na massa" e efetivamente contribuir com a pesquisa e a redação/revisão do artigo, ou com a adaptação do trabalho para o formato de artigo, com revisões críticas concretas.

Em relação às pessoas que não cumprirem com os critérios mínimos para autoria, mas contribuíram com a pesquisa, deve-se reconhecer e agradecer tais funções no item de "agradecimentos" no artigo, normalmente ao final ou em nota de rodapé inicial. ${ }^{18}$ Ali devem ser indicados também os financiamentos que foram fornecidos à pesquisa, como eventuais bolsas e projetos. Deve-se ressaltar que a inclusão de nomes no item de agradecimentos precisa ser informada e expressamente autorizada pelo pesquisador a quem se pretende citar. Trata-se de medida fundamental para assegurar o consentimento de quem é mencionado no artigo, visto que tal ato pode ocasionar certo comprometimento com o papel indicado em tal agradecimento.

A ordem de indicação dos nomes dos coautores na lista também é objeto de debates, pois há distintas interpretações sobre a importância do primeiro e do último nome. ${ }^{19}$ Em regra, pensa-se que a ordem deve refletir a relevância das contribuições de cada autor para a pesquisa, da

18 CONCEIÇÃO, Maria Inês G. Editorial: os colaboradores em um artigo científico. Psicologia: teoria e pesquisa, Brasília, v. 24, n. 2, p. iii-iv, abr./jun. 2008. p. iii.

19 PETROIANU, Andy. Critérios para autoria de um trabalho científico. DST Jornal brasileiro de doenças sexualmente transmissíveis, v. 24, n. 2, p. 99-103, 2012. p. 99. 
maior até a menor. ${ }^{20}$ Há quem proponha, por exemplo, pontuação para cada função desempenhada, de modo à listagem refletir tal resultado. ${ }^{21}$

Diante de tais premissas e discussões, a RBDPP adota parâmetros para integridade científica em questões de coautoria em publicações no periódico. Primeiramente, adota-se uma limitação quantitativa ao número de autores em um artigo: "Os trabalhos podem ter, no máximo, três autores. Em casos de pesquisas empíricas e/ou de complexidade ímpar, que necessitem de mais colaboradores, deverá ser enviada motivação, que explique tal situação e indique concretamente a contribuição de cada autor". ${ }^{22}$ Pensa-se que, preliminarmente, a fixação de um número objetivo máximo de autores é recomendada para evitar abusos e más-práticas de um modo abstrato. Contudo, sabe-se que existem casos de pesquisas complexas, especialmente quando envolvem metodologias empíricas e coleta de dados, de modo que em casos justificados há a possibilidade de ampliação do número de autores.

Além da limitação objetiva, a RBDPP também adota parâmetros para descrição qualitativa de coautoria. Nos termos das políticas de integridade para autores: "Quando se tratar da publicação de resultados obtidos por meio de pesquisa coletiva, é preciso certificar-se da contribuição intelectual direta e efetiva e do consentimento de todos os colaboradores. A cessão de recursos financeiros e de infraestrutura não é indicação de coautoria.” ${ }^{23}$ Além disso, ali também são reproduzidas orientações do CNPq sobre a temática:

20 MONTENEGRO, Mario R. Autoria e co-autoria: justificativa e desvios. Jornal Brasileiro de Pneumologia, v. 25, n. 3, p. 159-162, mai./jun. 1999. p. 160; WITTER, Geraldina Porto. Ética e autoria na produção textual científica. Informação \& Informação, Londrina, v. 15, n. esp., p. 131-144, 2010. p. 138.

21 Nesse sentido: PETROIANU, Andy. Critérios para autoria de um trabalho científico. DST - Jornal brasileiro de doenças sexualmente transmissíveis, v. 24, n. 2, p. 99-103, 2012.

22 RBDPP, Diretrizes para autores. Disponível em: <http://www.ibraspp.com. $\mathrm{br} /$ revista/index.php/RBDPP/about/submissions\#authorGuidelines>. Acesso em: 23 dez. 2019.

23 RBDPP, Pressupostos de integridade ética a autores. Disponível em: <http:// www.ibraspp.com.br/revista/index.php/RBDPP/about/editorialPolicies\#custom-2>. Acesso em: 23 dez. 2019. 
"16. A inclusão de autores no manuscrito deve ser discutida antes de começar a colaboração e deve se fundamentar em orientações já estabelecidas, tais como as do International Committee of Medical Journal Editors.

17. Somente as pessoas que emprestaram contribuição significativa ao trabalho merecem autoria em um manuscrito. Por contribuição significativa entende-se realização de experimentos, participação na elaboração do planejamento experimental, análise de resultados ou elaboração do corpo do manuscrito. Empréstimo de equipamentos, obtenção de financiamento ou supervisão geral, por si só não justificam a inclusão de novos autores, que devem ser objeto de agradecimento.

18. A colaboração entre docentes e estudantes deve seguir os mesmos critérios. Os supervisores devem cuidar para que não se incluam na autoria estudantes com pequena ou nenhuma contribuição nem excluir aqueles que efetivamente participaram do trabalho. Autoria fantasma em Ciência é eticamente inaceitável."24

Para assegurar a conformidade e a ciência dos autores em relação a tais diretrizes, em caso de artigos em coautoria, a RBDPP solicita a inclusão de declaração de coautoria ao final do trabalho para publicação, onde se especificarão as contribuições de cada autor. Trata-se de medida incentivada por órgãos internacionais de integridade científica para que as revistas científicas adotem posturas ativas com o objetivo de evitar más-práticas em questões relacionadas a coautoria. ${ }^{25}$ Nesses termos, atualmente insere-se modelo de declaração, que deve ser revisado e complementado pelos autores no momento das rodadas de correções dos artigos aprovados. ${ }^{26}$

24 CNPq. Diretrizes básicas para a integridade na atividade científica. Disponível em: <http://cnpq.br/diretrizes>. Acesso em: 23 dez. 2019.

25 Nesse sentido: <http://www.icmje.org/recommendations/browse/roles -and-responsibilities/defining-the-role-of-authors-and-contributors.html>. Acesso em: 23 dez. 2019. Sobre a adoção de tais declarações e da terminologia CReditCasrai: <https://blogs.plos.org/plos/2016/07/author-credit-plos -and-credit-update/>. Acesso em: 23 dez. 2019.

26 Sobre as rodadas de correções, ver: VASCONCELLOS, Vinicius G. Editorial: As rodadas de correções e a carta-resposta do autor à aprovação condicionada - sobre o controle e o aprimoramento dos artigos no processo editorial 
No modelo de declaração de coautoria são indicados os seguintes papeis possíveis (que devem ser especificados para cada autor no que for pertinente): projeto e esboço inicial (conceptualization), desenvolvimento da metodologia (methodology), coleta e análise de dados (data curation), levantamento bibliográfico (investigation), revisão bibliográfica (investigation), redação (writing - original draft), participação ativa nas discussões dos resultados (validation), revisão crítica com contribuições substanciais (writing - review and editing), aprovação da versão final. Adota-se aqui terminologia em conformidade com as definições traçadas no Projeto CRedit (Contributor Roles Taxonomy) ${ }^{27}$ do CASRAI.

Assim, ao final de cada artigo publicado na RBDPP são incluídas declarações de integridade dos autores. Em relação à coautoria, os autores atestam que "todas e somente as pessoas que atendem aos requisitos de autoria deste artigo estão listadas como autores; todos os coautores se responsabilizam integralmente por este trabalho em sua totalidade". Em casos de coautoria, logo após insere-se listagem dos autores, com a especificação de suas contribuições nos termos acima referidos.

Importante perceber que a especificação das contribuições dos autores, nos termos solicitados pela RBDPP, não impõe necessariamente que haja a indicação dos trechos ou capítulos do artigo que foram escritos por cada autor. O que se impõe, em verdade, é a descrição das funções e contribuições de cada indivíduo no processo de desenvolvimento da pesquisa que originou o artigo.

Por fim, vale destacar que a tarefa de definição da listagem de coautores e agradecimentos é função dos pesquisadores envolvidos no trabalho. O periódico científico e sua equipe editorial devem adotar medidas para conscientizar e tentar evitar más-práticas em tal seara, mas não são responsáveis por determinar quem se qualifica ou não à autoria. Em casos de conflitos entre pesquisadores em relação a tais questões, recomenda-se que as instituições a eles vinculadas devam ser responsáveis pela

científico. Revista Brasileira de Direito Processual Penal, Porto Alegre, vol. 3, n. 3, p. 757-768, set./dez. 2017.

27 Disponível em: <https://casrai.org/credit/>. Acesso em 23 dez. 2019. 
solução e eventual investigação. ${ }^{28}$ Nos termos das orientações do COPE, se houver necessidade de alteração da lista de autores após a submissão (adição, exclusão ou alteração da ordem), todos os coautores indicados precisam consentir expressamente e deve haver motivação para tanto. ${ }^{29}$

Portanto, diante de todo o aqui exposto, recomenda-se que os autores, antes da submissão do artigo, conversem especificamente sobre questões de coautoria e tenham consenso sobre: 1) quem vai ser incluído na lista de autores; 2) quais contribuições cada autor realizou no processo de desenvolvimento da pesquisa e do artigo; 3 ) em qual ordem os autores serão indicados na lista; 4) quem será apontado no item de agradecimentos.

\section{REFERÊNCIAS}

BRAND, Amy; ALLEN, Liz; ALTMAN, Micah; HLAVA, Marjorie; SCOTT, Jo. Beyond authorship: attribution, contribution, collaboration, and credit. Learned Publishing, v. 28, n. 2, p. 151-155, 2015. https://doi.org/10.1087/20150211

CAPPARELLI, Bruna; GIACOMOLLI, Nereu J. Editorial: A avaliação do Impact Factor na publicação científica de Direito Processual Penal. Revista Brasileira de Direito Processual Penal, Porto Alegre, vol. 3, n. 3, p. 789-806, set./dez. 2017. https://doi.org/10.22197/rbdpp.v3i3.108

CONCEIÇÃO, Maria Inês G. Editorial: os colaboradores em um artigo científico. Psicologia: teoria e pesquisa, Brasília, v. 24, n. 2, p. iii-iv, abr./jun. 2008. https:// doi.org/10.1590/S0102-37722008000200001

DONATO, Helena. Autoria na publicação científica. Revista da Sociedade Portuguesa de Medicina Física e Reabilitação, v. 25, n. 1, p. 8-10, 2014.

${ }^{28}$ Nesse sentido: <http://www.icmje.org/recommendations/browse/roles -and-responsibilities/defining-the-role-of-authors-and-contributors.html>. Acesso em: 23 dez. 2019. Sobre isso, ver: COPE. Documento de discussão: Autoria. Disponível em: <https://publicationethics.org/files/COPE_DD_A4_ Authorship_SEPT19_SCREEN_AW.pdf $>$. Acesso em: 23 dez. 2019.

Disponível em: <https://publicationethics.org/authorship>. Acesso em: 23 dez. 2019. 
KROKOSCZ, Marcelo. Autoria na redação científica. Informação \& Informação, Londrina, v. 20, n. 1, p. 319-333, jan./abr. 2015. https://doi. org/10.5433/1981-8920.2015v20n1p319

MINORELLI, Lucas; SILVA, Willians M. Publicações em periódicos de ciências criminais no Brasil: uma perspectiva de editores. Revista dos Tribunais, São Paulo, v. 1009, p. 359-381, nov. 2019.

MONTEIRO, Rosangela; JATENE, Fabio B.; GOLDENBERG, Saul; POBLACIÓN, Dinah A.; FELLIZZON, Rosely F. Critérios de autoria em trabalhos científicos: um assunto delicado e polêmico. Revista Brasileira de Cirurgia Cardiovascular, v. 19, n. 4, p. III-VIII, 2004. https://doi.org/10.1590/s0102-76382004000400002

MONTENEGRO, Mario R. Autoria e co-autoria: justificativa e desvios. Jornal Brasileiro de Pneumologia, v. 25, n. 3, p. 159-162, mai./jun. 1999.

PETROIANU, Andy. Critérios para autoria de um trabalho científico. DST - Jornal brasileiro de doenças sexualmente transmissíveis, v. 24, n. 2, p. 99-103, 2012.

REGO, Sergio. Índice $\mathrm{H}$, Autoria e Integridade na Produção Científica. Revista Brasileira de Educação Médica, Rio de Janeiro, v. 34, n. 2, p. 189-190, abr./jun. 2010. https://doi.org/10.1590/S0100-55022010000200001

VASCONCELLOS, Vinicius G. Editorial: a função do periódico científico e do editor para a produção do conhecimento no Direito e nas ciências criminais. Revista Brasileira de Direito Processual Penal, Porto Alegre, vol. 3, n. 1, p. 9-17, jan./abr. 2017. https://doi.org/10.22197/rbdpp.v3i1.34

VASCONCELLOS, Vinicius G. Editorial: As rodadas de correções e a carta-resposta do autor à aprovação condicionada - sobre o controle e o aprimoramento dos artigos no processo editorial científico. Revista Brasileira de Direito Processual Penal, Porto Alegre, vol. 3, n. 3, p. 757-768, set./dez. 2017. https://doi.org/10.22197/ rbdpp.v3i3.101

WINCK, J.C.; WEDZICHA, J.A.; FONSECA, J.A.; AZEVEDO, L.F. To publish or perish: how to review a manuscript. Revista Portuguesa de Pneumología, vol. 17, n. 2, p. 96-103, 2011. https://doi.org/10.1016/s2173-5115(11)70022-7

WITTER, Geraldina Porto. Ética e autoria na produção textual científica. Informação \& Informação, Londrina, v. 15, n. esp., p. 131-144, 2010. https://doi. org/10.5433/1981-8920.2010v15nespp131 


\section{Informações adicionais e declarações do autor (integridade científica)}

Agradecimentos (acknowledgement): Agradeço a Lucas Minorelli, Fayga Bedê e Rogério Borba pela leitura do texto em preprint com envio de sugestões e críticas relevantes.

Declaração de conflito de interesses (conflict of interest declaration): o autor confirma que não há conflitos de interesse na realização das pesquisas expostas e na redação deste editorial.

Declaração de autoria (declaration of authorship): todas e somente as pessoas que atendem aos requisitos de autoria deste editorial estão listadas como autores.

Declaração de ineditismo e originalidade (declaration of originality): o autor assegura que o texto aqui publicado não foi divulgado anteriormente em outro meio e que futura republicação somente se realizará com a indicação expressa da referência desta publicação original; também atesta que não há plágio de terceiros ou autoplágio.

\section{COMO CITAR ESTE EDITORIAL:}

VASCONCELLOS, Vinicius G. Editorial - Autoria e coautoria de trabalhos científicos: discussões sobre critérios para legitimação de coautoria e parâmetros de integridade científica. Revista Brasileira de Direito Processual Penal, Porto Alegre, vol. 6, n. 1, p. 13-26, jan./abr. 2020. https://doi.org/10.22197/rbdpp.v6i1.313

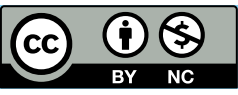

Esta obra está licenciada com uma Licença Creative Commons Atribuição-NãoComercial 4.0 Internacional. 